\title{
Implementasi Teknik Remarketing Menggunakan Tools Google Analytics untuk Melakukan Promosi PMB Tertarget
}

\author{
Yopi Hidayatul Akbar \\ STMIK Sumedang \\ yopi@stmik-sumedang.ac.id
}

\begin{abstract}
Marketing strategy is very important for companies where marketing strategy is a way of achieving the goals of a company, because the potential to sell a proposition is limited to the number of people who see it. With the conventional marketing concept, the target to achieve the goal cannot be maximized, it only eliminates time and cost. With the large number of smartphone users and information technology today, digital marketing techniques will be more efficient, because marketing targets can be managed to only certain segments. The application of remarketing techniques is of course not only done by google analytics, but also Facebook ads to monitor events or user interactions with ads that have reached certain locations. At this time, implementing the remarketing method on Google Analytics and Facebook Ads by utilizing research events and ad conversion so that data that has interacted with ads on Facebook will also enter into tracking data. From the analysis of the results that have been carried out by the author, it can be concluded that online marketing techniques with the application of appropriate remarketing techniques will be able to increase visitor traffic. The evaluation results are expected to be a good solution and recommendations for online promotion so that the results can be targeted as expected.
\end{abstract}

Keywords : Marketing, Digital, Remarketing, Online.

\begin{abstract}
ABSTRAK
Strategi pemasaran merupakan hal yang sangat penting bagi perusahaan di mana strategi pemasaran merupakan suatu cara mencapai tujuan dari sebuah perusahaan, karena potensi untuk menjual proposisi terbatas pada jumlah orang yang mengetahui hal tersebut. Dengan konsep pemasaran secara konvensional, target untuk mencapai tujuan tidak dapat maksimal, bahkan hanya membuang waktu dan biaya saja. Dengan banyaknya pengguna smartphone dan teknologi informasi saat ini, teknik pemasaran secara digital akan lebih efisien, karena target pemasaran dapat di arahkan ke segmen tertentu saja. Penerapan teknik remarketing tentunya tidak hanya dilakukan oleh google analytics saja melainkan bisa juga dilakukan oleh facebook ads untuk melacak event maupun interaksi pengguna dengan iklan yang telah menjangkau lokasi tertentu. Pada penelitian ini, melakukan penerapan metode remarketing pada Google Analytics dan Facebook Ads dengan memanfaatkan event dan konversi iklan sehingga data pengguna yang pernah melakukan interaksi dengan iklan yang ada di Facebook juga akan masuk kedalam data tracking. Dari hasil analisis yang telah dilakukan oleh penulis maka dapat diambil kesimpulan bahwa teknik pemasaran online dengan penerapan teknik remarketing yang tepat maka akan dapat meningkatkan trafik pengunjung. Hasil evaluasi yang dilakukan diharapkan dapat menjadi solusi dan rekomendasi yang baik dalam melakukan promosi online agar hasilnya dapat tertarget sesuai dengan yang diharapkan.
\end{abstract}

Kata Kunci : Pemasaran, Digital, Remarketing, Online. 


\section{Information System Journal}

\section{PENDAHULUAN}

\subsection{Latar Belakang Masalah}

Internet dalam bisnis digunakan untuk pertukaran informasi, katalog produk, media promosi, surat elektronik, bulletin boards, kuesioner elektronik, dan mailing list. Internet juga bisa digunakan untuk berdialog, berdiskusi, dan konsultasi dengan konsumen secara online [1], sehingga konsumen dapat dilibatkan secara proaktif dan interaktif dalam perancangan, pengembangan, pemasaran, dan penjualan produk. Pemasaran lewat internet ada 2 metode, yaitu push dan pull marketing.

Keunggulan strategi bisnis yang dapat diperoleh dari internet adalah komunikasi global dan interaktif; menyediakan informasi dan pelayanan sesuai dengan kebutuhan konsumen; meningkatkan kerja sama; memungkinkan untuk membuka pasar, produk, atau pelayanan baru serta mengintegrasikan aktivitas secara on-line [2]. Aplikasi Electronic Commerce ada 2, yaitu: Business-to-Consumer dan Business-to-Business Commerce. Pembayaran transaksi electronic commerce diatur dalam Sistem Electronic Funds Transfer, sedangkan keamanan datanya diatur oleh Secure Socket Layer yang dikembangkan menjadi Secure Electronic Transaction.

Pada saat ini perkembangan pemasaran secara online sudah banyak diterapkan oleh berbagai perusahaan maupun usaha kecil menengah (UKM), pentingnya strategi pemasaran adalah untuk meningkatkan brand awareness [3] atau kesadaran merek kepada masyarakat yang mana kesadaran merk merupakan salah satu pertimbangan dalam melihat perilaku konsumen, pengelolaan periklanan, pengelolaan merk serta pengembangan strategi yang akan dijalankan.

Salah satu faktor kunci keberhasilan usaha di dunia internet adalah dengan menjalankan perikalanan secara online, berbeda dengan jaman dahulu teknik periklanan hanya dilakukan dengan memasang informasi di media cetak, koran maupun radio, namun saat ini strategi periklanan tersebut sudah dianggap kurang efektif karena saat ini sebagian besar orang sudah dapat mengakses internet untuk menacari informasi maupun sekedar membaca berita melalui berbagai aplikasi. Peran aktif mesin pencari Google dalam periklanan online adalah hal yang menjadi fokus peneliti dalam melakukan evaluasi periklanan yang dilakukan secara online saat ini[4][5], hal itu dikarenakan hampir sebagaian besar orang mencari informasi melalui mesin pencari Google untuk mendapatkan informasi mengenai produk atau jasa yang diperlukan.

Pada waktu sekarang ini beberapa perusahaan, lembaga pendidikan maupun usaha kecil menengah saat ini sudah menjalankan perikalan melalui online dengan menggunakan Google Ads, Facebook Ads maupun Instagram Ads, akan tetapi mereka belum mengetahui cara yang tepat untuk memasarkan produk maupun jasa yang akan ditawarkan kepada masyarakat agar tepat guna dan tepat sasaran [3]sehingga menghindari pengeluaran anggaran iklan yang tidak efektif.

Dalam menjalankan pemasaran secara online diperlukan suatu media website untuk menampung segala informasi yang akan disampaikan kepada masyarakat berkaitan dengan produk maupun jasa agar masyarakat dapat mengetahui produk atau jasa apa saja yang akan ditawarkan[2]. Website merupakan salah satu media informasi yang sekarang ini banyak digunakan oleh beberapa perusahaan, lembaga pendidikan maupun personal untuk menyampaikan informasi, dengan adanya media website perusahaan tidak perlu lagi menyebarkan informasi atau berita melalui media cetak, mereka dapat menggunakan sarana teknologi informasi dalam hal ini website untuk menyampaikan informasi kepada para pengguna secara global melalui internet[2].

Pada saat proses pemasaran dijalankan tentunya setiap pengguna akan melihat konten dan informasi yang terkandung dalam iklan tersebut yang dapat memberikan minat untuk melakukan klik terhadap konten iklan tersebut, dari interaksi klik pengguna akan diarahkan ke website untuk dapat membaca informasi secara detail mengenai komposisi dari informasi yang disampaikan. Oleh karena itulah peneliti akan melakukan penelitian mengenai strategi 


\section{Information System Journal}

remarketing menggunakan google analytics[2][6], hal itu dilakukan agar setiap iklan yang dijalankan dapat di analisis dan di evaluasi untuk dapat diterapkan ke pemasaran yang akan datang. Proses analisis dilakukan dari berbagai faktor, salah satunya adalah dilihat dari trafik pengunjung per bulan, perangkat yang digunakan, jaringan provider, asal kota, sistem operasi, browser, jenis kelamin, dan usia pengunjung. Berdasarkan data tersebut maka kita bisa melakukan evaluasi terhadap hasil yang telah dijalankan dengan melakukan remarketing agar tujuan pemasaran yang kita lakukan dapat tertarget sesuai dengan yang diharapkan.

Google Analytics merupakan salah satu layanan dari Google yang dapat memberikan informasi statistik pengunjung pada sebuah situs web[5]. Google Analytics dapat menelusuri pengunjung berdasarkan informasi halaman pengacu, termasuk mesin pencari, iklan, jaringan pay-per-click, email marketing, dan juga tautan yang terkandung dalam dokumen PDF[3]. Jika diintegrasikan dengan AdWords, Google Analytics juga bermanfaat untuk menganalisis efektfitas iklan AdWords yang dipasang di Google. Dengan Google Analytics, pengguna dapat mengetahui iklan dan kata kunci apa yang paling banyak merujuk ke situs web pengguna.

Aplikasi Google Analytics dapat di akses melalui alamat google.com/analytics/. Google Analytics juga digunakan untuk mengetahui kepadatan trafik dari website/blog. Dengan menggunakan Google Analytics seseorang dapat membuat report tentang trafik website/blog dalam jangka waktu harian, mingguan, atau bulanan. Untuk mendaftar pada Google Analytics, seseorang hanya perlu memiliki akun Google.

\subsection{Tinjauan Pustaka}

Strategi pemasaran merupakan hal yang sangat penting bagi perusahaan di mana strategi pemasaran merupakan suatu cara mencapai tujuan dari sebuah perusahaan, karena potensi untuk menjual proposisi terbatas pada jumlah orang yang mengetahui hal tersebut. Hal ini juga didukung oleh pendapat Swastha "Strategi adalah serangkaian rancangan besar yang menggambarkan bagaimana sebuah perusahaan harus beroperasi untuk mencapai tujuannya." Sehingga dalam menjalankan usaha kecil khususnya diperlukan adanya pengembangan melalui strategi pemasarannya. Karena pada saat kondisi kritis justru usaha kecillah yang mampu memberikan pertumbuhan terhadap pendapatan masyarakat.

Pemasaran ulang adalah cara terbaik untuk terhubung dengan pengunjung ke situs web yang mungkin belum melakukan pembelian atau penyelidikan segera. Ini memungkinkan kita untuk memposisikan iklan bertarget kepada audiens yang sudah ditentukan yang sebelumnya mengunjungi situs web Anda[3]. Iklan pemasaran ulang Anda dapat tampil di situs web mana pun yang menerima iklan dari Jaringan Display Google mencakup banyak situs web lokal paling populer[4]. Ada tingkat fleksibilitas penargetan yang tinggi dan Anda bahkan dapat memfilter penargetan hanya untuk ditampilkan di situs tertentu dan atau mengecualikan situs tertentu. Banyak klien kami menemukan pemasaran ulang sebagai bentuk iklan yang sangat (sangat) hemat biaya untuk mengingatkan pengunjung agar membeli penawaran Anda dan meningkatkan kesadaran merek. Untuk bisnis apa pun dengan situs web, jika Anda mempertimbangkan beriklan online, para ahli kami sangat merekomendasikan berinvestasi di beberapa pemasaran ulang.

Google adalah sebuah perusahaan multinasional Amerika Serikat yang berkekhususan pada jasa dan produk Internet. Produk-produk tersebut meliputi teknologi pencarian, komputasi web, perangkat lunak, dan periklanan daring. Sebagian besar labanya berasal dari AdWords. Google didirikan oleh Larry Page dan Sergey Brin saat masih mahasiswa Ph.D. di Universitas Stanford. Mereka berdua memegang 16 persen saham perusahaan. Mereka menjadikan Google sebagai perusahaan swasta pada tanggal 4 September 1998[2]. Pernyataan misinya adalah "mengumpulkan informasi dunia dan membuatnya dapat diakses dan bermanfaat oleh semua orang. 


\section{Information System Journal}

Sejak didirikan, pertumbuhan perusahaan yang cepat telah menghasilkan berbagai produk, akuisisi, dan kerja sama di bidang mesin pencari inti Google. Perusahaan ini menawarkan perangkat lunak produktivitas daring (dalam jaringan), termasuk surat elektronik (surel), paket aplikasi perkantoran, dan jejaring sosial. Produk-produk komputer mejanya meliputi aplikasi untuk menjelajah web, mengatur dan menyunting foto, dan pesan instan. Perusahaan ini memprakarsai pengembangan sistem operasi Android untuk telepon genggam dan Google Chrome OS untuk jajaran netbook Chromebook. Google sudah beralih ke perangkat keras komunikasi. Mereka bekerja sama dengan berbagai produsen elektronik besar untuk memproduksi perangkat Nexus-nya dan mengakuisisi Motorola Mobility pada Mei 2012.Tahun 2012, infrastruktur serat optik dipasang di Kansas untuk memfasilitasi layanan Internet pita lebar Google Fiber.

Perusahaan ini diperkirakan mengoperasikan lebih dari satu juta server di beberapa pusat data di seluruh dunia dan memproses lebih dari satu miliar kueri pencarian dan sekitar 24 petabita data buatan pengguna setiap harinya. Pada bulan Desember 2012, Alexa menyebut google.com sebagai situs web paling banyak dikunjungi di dunia. Situs-situs Google dalam bahasa lain masuk peringkat 100 teratas, sebagaimana halnya situs milik Google seperti YouTube dan Blogger. Google menempati peringkat kedua di basis data ekuitas merek BrandZ. Dominasi pasarnya menuai kritik mengenai hak cipta, penyensoran, dan privasi. Pada tahun 2014, Google juga mendapat penghargaaan dari Business Indeed sebagai perusahaan yang memiliki merk paling bernilai.

Dikutip dari situs wikipedia Google Search adalah mesin pencari web yang dimiliki Google Inc. Google Search adalah mesin pencari yang paling banyak digunakan di dunia maya. Sekian ratus juta kueri dimasukkan setiap harinya oleh para peselancar web melalui berbagai macam layanan yang disediakan. Urutan hasil pencarian Google sebagian didasarkan pada peringkat prioritas bernama "PageRank". Google Search memberikan banyak pilihan pencarian kustom dengan operator Boolean seperti: pengecualian ("-xx"), alternatif ("xx OR yy"), dan kartu liar ("x* x").

Tujuan utama Google Search adalah mencari teks di dokumen-dokumen publik yang tersedia di server web (dalam format HTML, PDF, etc.), berbeda dengan data-data lain yang dapat dicari menggunakan layanan semacam Google Image Search. Google Search awalnya dikembangkan oleh Larry Page dan Sergey Brin pada tahun 1997. Google Search menyediakan sedikitnya 22 fitur istimewa selain pencarian kata, yaitu sinonim, ramalan cuaca, zona waktu, pergerakan saham, peta, data gempa, jadwal bioskop, bandar udara, daftar rumah, dan skor olahraga. Ada pula fitur istimewa untuk penanggalan, termasuk rentang angka (70..73), harga, suhu, konversi mata uang ("10.5 $\mathrm{cm}$ in inches"), perhitungan (" $3 * 4+\operatorname{sqrt}(6)-$ pi/2"), pelacakan paket, paten, kode wilayah, dan penerjemahan bahasa. Pada bulan Juni 2011, Google meluncurkan "Google Voice Search" dan "Search by Image" yang memungkinkan pengguna mencari sesuatu dengan perintah suara dan gambar. Bulan Mei 2012, Google memperkenalkan fitur pencarian semantik Knowledge Graph untuk kawasan Amerika Serikat.

Frekuensi pemakaian sejumlah kueri pencarian telah mencapai tingkatan volume tertentu yang menunjukkan tren ekonomi, sosial, dan kesehatan yang lebih luas. Data mengenai frekuensi pemakaian kueri pencarian di Google (tersedia melalui Google Adwords, Google Trends, dan Google Insights for Search) telah dipakai untuk mengaitkan wabah flu dengan tingkat pengangguran dan menyampaikan informasi lebih cepat daripada metode reportase tradisional dan survei pemerintah.

Google Analytics layanan gratis dari Google yang menampilkan statistik pengunjung sebuah situs web. Google Analytics dapat menelusuri pengunjung berdasarkan informasi halaman pengacu, termasuk mesin pencari, iklan, jaringan pay-per-click, email marketing, dan juga tautan yang terkandung dalam dokumen PDF. Jika diintegrasikan dengan AdWords, Google Analytics juga bermanfaat untuk menganalisis efektfitas iklan AdWords yang dipasang 


\section{Information System Journal}

di Google. Dengan Google Analytics, pengguna dapat mengetahui iklan dan kata kunci apa yang paling banyak merujuk ke situs web pengguna. Aplikasi Google Analytics dapat di akses melalui alamat google.com/analytics/. Google Analytics juga digunakan untuk mengetahui kepadatan trafik dari website/blog. Dengan menggunakan Google Analytics seseorang dapat membuat report tentang trafik website/blog dalam jangka waktu harian, mingguan, atau bulanan. Untuk mendaftar pada Google Analytics, seseorang hanya perlu memiliki akun Google.

Google AdWords adalah sebuah produk periklanan yang dibuat oleh Google yang sampai saat ini masih menjadi sumber pemasukan utama Google di bidang periklanan. Google AdWords adalah sebuah strategi pemasaran periklanan baru yang menggunakan mesin pencarian Google sebagai saran beriklan, biasa disebut juga sebagai Search Engine Marketing atau pemasaran berbasis mesin pencari. Google AdWords mempunyai dua cara beriklan, yaitu:

1) Sistem PPM atau Pay Per Million Impressions, di mana para pengiklan membayar produk yang diiklankan melalui Google berdasarkan jumlah per seribu impressions atau tayang nya iklan tersebut.

2) Sistem PPC atau Pay Per Click, di mana para pengiklan membayar iklan berdasarkan jumlah klik yang didapt dari iklan tersebut. Jadi apabila iklan tersebut tampil di mesin pencarian Google namun tidak ada yang melakukan klik, maka pengiklan tidak akan membayar biaya tayang iklannya.

Strategi Google AdWords adalah dengan menargetkan Kata Kunci atau keyword pencarian. Jadi kita bisa menargetkan iklan kita keluar pada kata kunci tertentu. Sebagai contoh apabila seseorang ingin mengiklankan mengenai rental mobil, maka dia bisa menargetkan keyword "sewa mobil" pada Google AdWords dan kemudian iklannya akan muncul pada hasil pencarian ketika orang memasukkan keyword "sewa mobil".

Platform Google AdWords terbagi 2, yaitu :

1) Google Search, di mana iklan kita muncul pada mesin pencarian Google. Platform search ini berdasarkan text dan keyword.

2) Google Display Network, di mana iklan kita akan muncul pada situs-situs yang termasuk ke dalam jaringan Google Display Network. Yaitu situs-situs yang memasang Google Adsense pada situsnya. Platform Display Network ini berdasarkan text, image, flash maupun video.

Google juga menyediakan alat (tool) Keyword Tool untuk melihat data mengenai jumlah pencarian dan tingkat kompetisi pemakaian suatu keyword untuk beriklan di AdWords. Selain itu dengan menggunakan Google Insight dan Google Trends kita juga dapat mengetahui trend keywords yang sedang banyak dicari oleh suatu masyarakat sehingga kita bisa menargetkan campaign iklan kita melalui keywords tersebut sesuai dengan tren yang berlaku saat ini. Situs resmi AdWords beralamat di http://www.google.com/adwords/. Namun tidak semua yang memasang iklan di Google memiliki kemampuan ataupun waktu untuk mengelola kampanye iklan secara efisien karena sangat banyak sistem pengaturan atau settings yang dapat mempengaruhi efektivitas kampanye iklan mereka. Masalah tersebut dapat di atasi oleh agen Adwords yang mempekerjakan seorang Adwords Qualified Individual yang mampu mengoptimalkan iklan, contohnya Golden e-Marketing, agar tidak ceroboh dan tanpa disadari membuang-buang anggaran budget Adwords-nya.

Dikutip dari situs wikipedia dapat dijelaskan bahwa Facebook adalah sebuah layanan jejaring sosial berkantor pusat di Menlo Park, California, Amerika Serikat yang diluncurkan pada bulan Februari 2004. Hingga September 2012, Facebook memiliki lebih dari satu miliar pengguna aktif, lebih dari separuhnya menggunakan telepon genggam. Pengguna harus mendaftar sebelum dapat menggunakan situs ini. Setelah itu, pengguna dapat membuat profil pribadi, menambahkan pengguna lain sebagai teman, dan bertukar pesan, termasuk pemberitahuan otomatis ketika mereka memperbarui profilnya. Selain itu, pengguna dapat 


\section{Information System Journal}

bergabung dengan grup pengguna dengan ketertarikan yang sama, diurutkan berdasarkan tempat kerja, sekolah atau perguruan tinggi, atau ciri khas lainnya, dan mengelompokkan teman-teman mereka ke dalam daftar seperti "Rekan Kerja" atau "Teman Dekat".

Facebook didirikan oleh Mark Zuckerberg bersama teman sekamarnya dan sesama mahasiswa Universitas Harvard, Eduardo Saverin, Andrew McCollum, Dustin Moskovitz, dan Chris Hughes. Keanggotaan situs web ini awalnya terbatas untuk mahasiswa Harvard saja, kemudian diperluas ke perguruan lain di Boston, Ivy League, dan Universitas Stanford. Situs ini secara perlahan membuka diri kepada mahasiswa di universitas lain sebelum dibuka untuk siswa sekolah menengah atas, dan akhirnya untuk setiap orang yang berusia minimal 13 tahun. Meski begitu, menurut survei Consumer Reports bulan Mei 2011, ada 7,5 juta anak di bawah usia 13 tahun yang memiliki akun Facebook dan 5 juta lainnya di bawah 10 tahun, sehingga melanggar persyaratan layanan situs ini.

Iklan Facebook atau Facebook Ads adalah fitur yang ditawarkan oleh Facebook untuk mempromosikan atau mengiklankan suatu Fan Page yang sebelumnya sudah dibuat oleh pengguna Facebook dengan jangkauan yang berbeda dan dapat diatur oleh pemasang iklan tersebut[7]. Facebook sendiri merupakan situs jejaring sosial dengan platform yang memungkinkan para penggunanya untuk menciptakan halaman pribadi, menambahkan teman, serta mengirim pesan. Situs jejaring sosial Facebook memiliki pengguna dengan lebih dari 1 miliar pengguna di seluruh dunia, sehingga dapat dikatakan bahwa Iklan Facebook merupakan iklan dengan jangkauan yang luas hingga dapat mencapai target 1 miliar pengguna di seluruh dunia. Dalam iklan Facebook, para pengiklan sebelumnya harus memiliki halaman Fan Page yang memungkinkan untuk para pengguna Facebook lainnya memberikan LIKE atau menjadi penggemar atas Fan Page tersebut, dan Fan Page tersebut dapat berupa perusahaan, produk layanan, individu, merek dagang, dan lain sebagainya[8]. Dalam perancangan iklannya, para pengiklan dapat dengan spesifik mengatur target pasar yang ingin mereka tuju, seperti wilayah geografi, gender atau jenis kelamin, umur, hal yang disukai, status pernikahan, pendidikan, dan lain sebagainya, dan setelah pengiklan memilih karakter target iklan apa saja yang akan dipilih, ia akan mengetahui berapa banyak jumlah target iklan mereka, dan hal tersebut membuat iklan yang dibuat menjadi lebih efektif dan tepat pada sasaran.

\section{METODOLOGI}

Penelitian ini dilakukan dengan menggunakan data primer dan sekunder. Data primer diperoleh melalui observasi dari situs website yang dilakukan penelitian dalam hal ini Perguruan Tinggi Indonesia Mandiri Bandung dengan mengambil data analisis bulan Maret dan April tahun 2017 sedangkan data sekunder diperoleh dari literatur-literatur yang dapat dijadikan sebagai masukan untuk penelitian. Proses analisis dan evaluasi yang dilakukan menggunakan tools Google Analytics.

Pentingnya penerapan teknik remarketing dalam periklanan untuk melakukan pemasaran ulang kepada pengguna yang pernah mengunjungi website kita sebelumnya, sehingga konten iklan yang kita jalankan dapat berjalan sesuai dengan target yang telah kita tentukan.

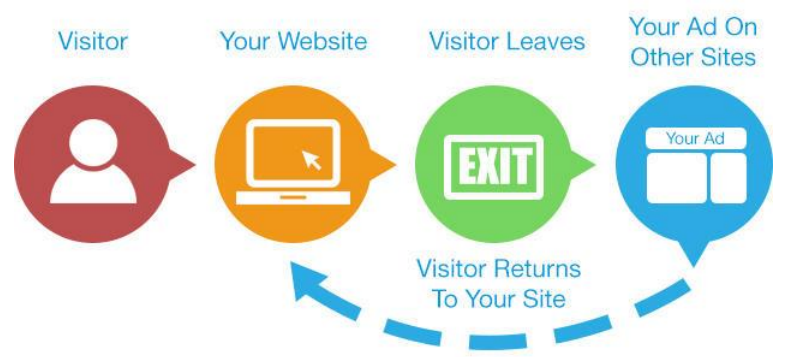

Gambar 1. Proses Remarketing Sumber : https://www.wordstream.com/ 


\section{Information System Journal}

Gambar di atas menunjukan proses remarketing periklanan yang diterapkan pada penelitian ini dengan langkah sebagai berikut :

1) Pengunjung mengunjungi website untuk mencari informasi yang diperlukan dengan sebelumnya mengklik konten iklan kita yang dijalankan melalui Google Ads, Facebook Ads dan Instagram Ads. Pada Search Engine Google dan media sosial

2) Sistem Google Aanalytics akan melakukan tracking pengunjung berdasarkan perangkat, sistem operasi, jaringan provider dan kota dimana pengunjung tersebut dapat melihat iklan yang kita tergetkan.

3) Pada Google Analytics kita melakukan generate kode tracking kemudian kita tanamkan di bagian header atau footer baris program website kita.

4) Konten iklan yang kita jalankan akan terus menampilkan iklan kepada pengunjung yang sebelumnya telah mengunjungi website kita karena data pengunjung website tersebut telah dilakukan tracking oleh google analytics.

\section{ANALISA DAN PERANCANGAN SISTEM}

Berikut ini adalah hasil remarketing yang telah dilakukan pada lembaga pendidikan Perguruan Tinggi Indonesia Mandiri Bandung dengan mengambil data pada bulan Maret dan April 2017.

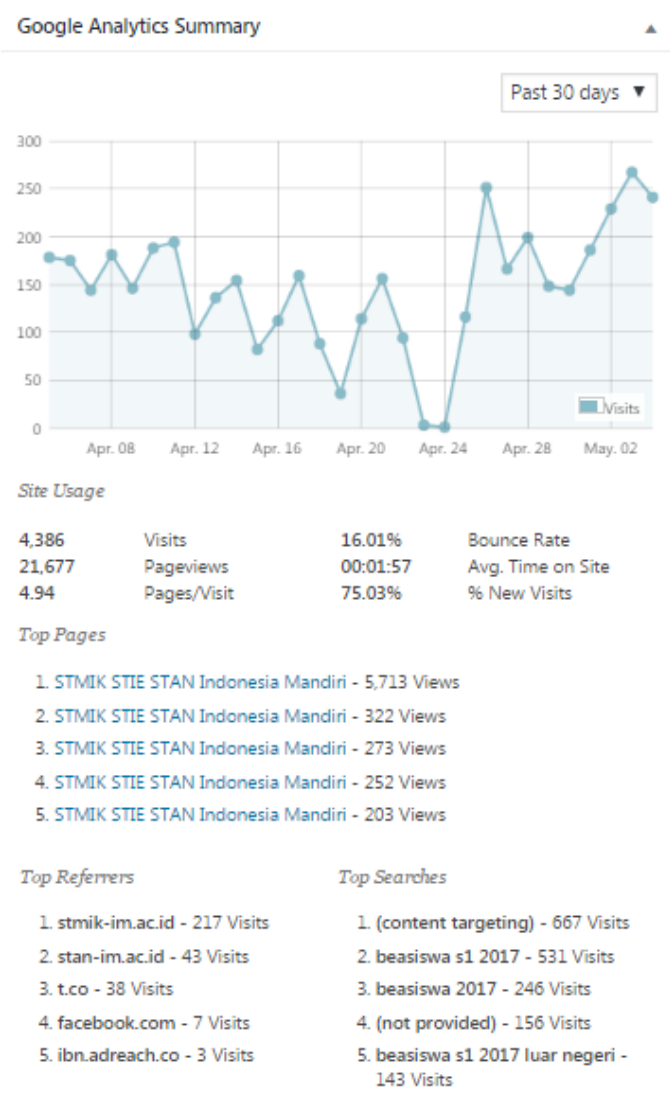

Gambar 2. Visitor Web pada Bulan April 2017

Pada gambar 2 menunjukan banyaknya visitor yang mengunjungi link penerimaan mahasiswa baru dengan banyak rujukan/backlink dari stmik-im, stan im, iklan facebook dan iklan adwords. 
Information System Journal

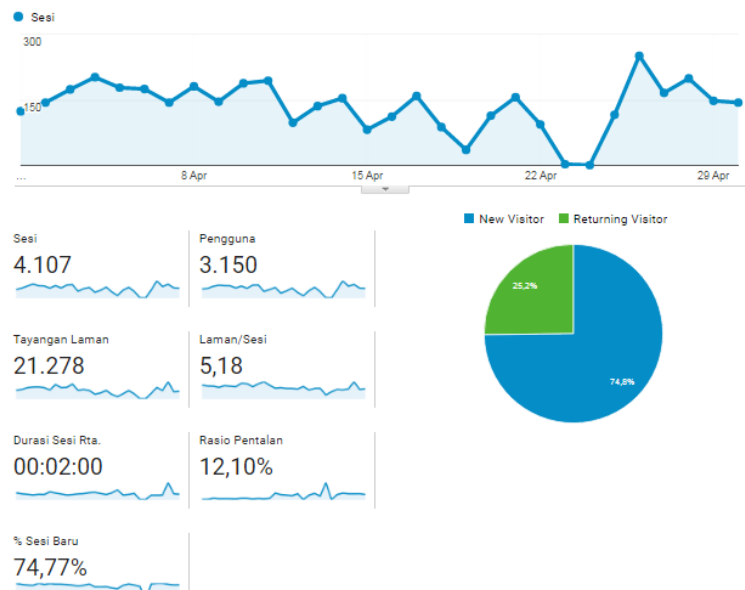

Gambar 3. Trafik Web Berdasarkan Google Analytics

Dari gambar 3 traffik pengunjung mengalami peningkatan sebesar 25,2\% pengunjung yang kembali mengunjungi website dan sebesar $74,80 \%$ pengunjung baru data analisis bulan Maret dan April tahun 2017.

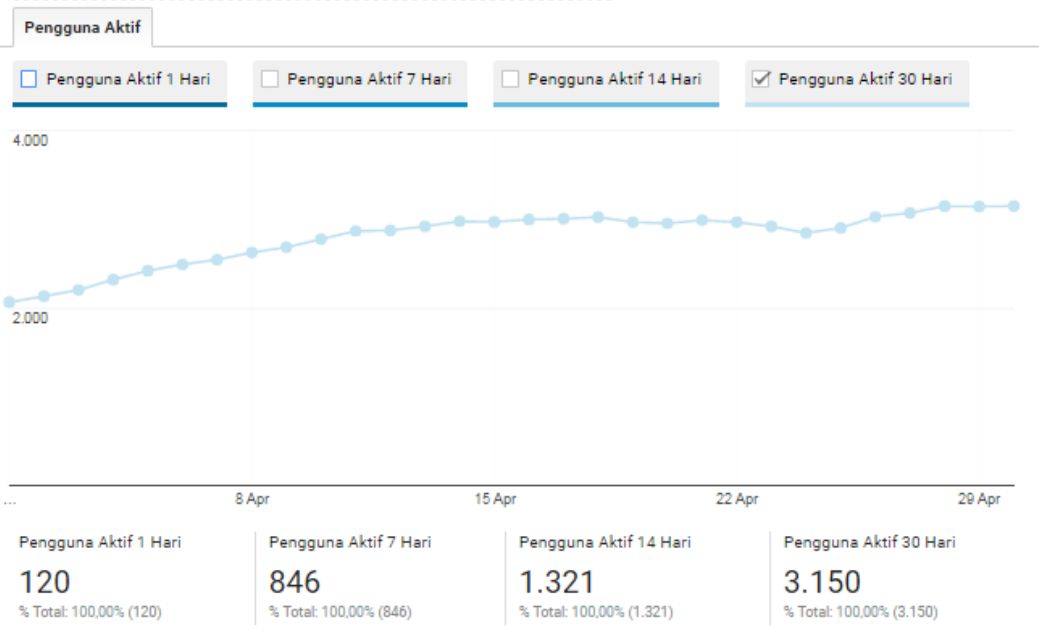

Gambar 4. Trafik Pengguna Aktif

Berdasarkan gambar 4 pengguna selama 30 hari mencapai 3,150 orang dengan rata-rata pengguna aktif sebanyak 120 / hari

\begin{tabular}{lrl|}
\multicolumn{1}{l}{ Kota } & Sesi & \% Sesi \\
\hline 1. Jakarta & 1.803 & $43,90 \%$ \\
\hline 2. Bandung & 1.512 & $36,82 \%$ \\
\hline 3. Surabaya & 160 & $3,90 \%$ \\
\hline 4. Medan & 136 & $3,31 \%$ \\
\hline 5. Makassar & 84 & $2.05 \%$ \\
\hline 6. (not set) & 52 & $1,27 \%$ \\
\hline 7. Bekasi & 41 & $1,00 \%$ \\
\hline 8. Bogor & 29 & $0.71 \%$ \\
\hline 9. Palembang & 25 & $0.61 \%$ \\
\hline 10. South Tangerang & 22 & $0,54 \%$ \\
\hline
\end{tabular}

Gambar 5. Trafik Berdasarkan Kota 
Berdasarkan gambar 5 dapat dilihat bahwa trafik terbesar adalah dari kota Jakarta dan Bandung, hal itu dikarenakan proses marketing ditargetkan di kota tersebut.

\begin{tabular}{|c|c|c|}
\hline Browser & Sesi & $\%$ Sesi \\
\hline 1. Chrome & 2.397 & $58,36 \%$ \\
\hline 2. Firefox & 507 & $12,34 \%$ \\
\hline 3. Android Webview & 310 & | $7.55 \%$ \\
\hline 4. UC Browser & 279 & | $6,79 \%$ \\
\hline 5. Safari & 231 & | $5.62 \%$ \\
\hline 6. Android Browser & 125 & | $3.04 \%$ \\
\hline 7. Opera Mini & 121 & | $2,95 \%$ \\
\hline 8. Opera & 86 & | $2,09 \%$ \\
\hline 9. BlackBerry & 19 & $0,46 \%$ \\
\hline 10. Edge & 11 & $0.27 \%$ \\
\hline
\end{tabular}

Gambar 6. Trafik Berdasarkan Browser

Berdasarkan gambar 6 dapat dijelaskan bahwa banyak pengguna yang mengunjungi website menggunakan browser Chrome, Firefox serta browser lainnya.

\begin{tabular}{lrl|}
\hline Sistem Operasi & Sesi $\%$ Sesi \\
\hline 1. Android & 2.583 & \multicolumn{2}{c|}{$62,89 \%$} \\
\hline 2. Windows & 1.191 & $29,00 \%$ \\
\hline 3. iOS & 244 & $5,94 \%$ \\
\hline 4. (not set) & 31 & $0,75 \%$ \\
\hline 5. BlackBerry & 19 & $0,46 \%$ \\
\hline 6. Macintosh & 15 & $0.37 \%$ \\
\hline 7. Linux & 14 & $0,34 \%$ \\
\hline 8. Windows Phone & 9 & $0,22 \%$ \\
\hline 9. Samsung & 1 & $0,02 \%$ \\
\hline & & lihat laporan lengkap \\
\hline
\end{tabular}

Gambar 7. Trafik Berdasarkan Sistem Operasi

Berdasarkan gambar 7 dapat dijelaskan bahwa banyak pengguna yang mengunjungi website menggunakan browser sistem operasi, Android, Windows, IOS serta OS lainnya.

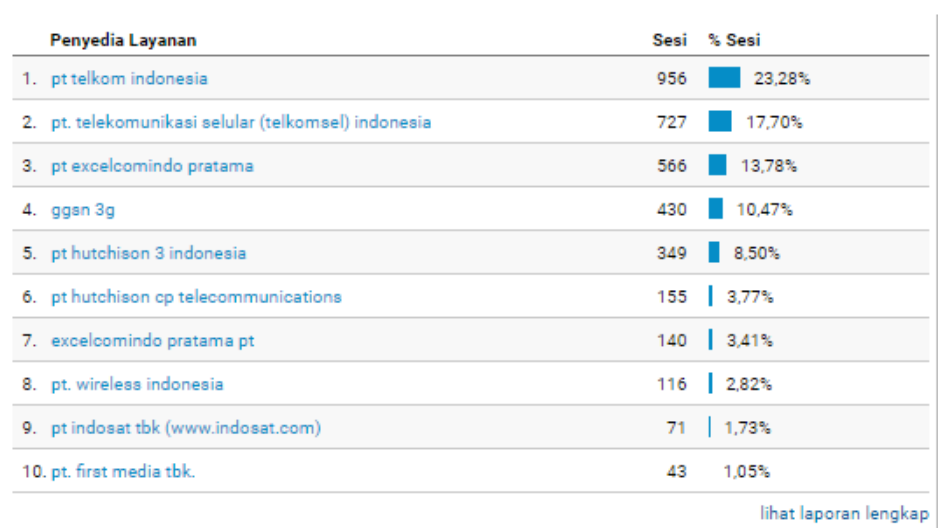

Gambar 8. Trafik Berdasarkan Penyedia Layanan

Berdasarkan gambar 8 dapat dijelaskan bahwa banyak pengguna yang mengunjungi website menggunakan jaringan Telkomsel, Excelcomindo serta provider lainnya. 
Tabel 1. Kategori Perangkat

\begin{tabular}{|c|c|c|c|c|c|c|c|c|c|}
\hline & \multirow[b]{3}{*}{ Kategori Perangkat } & & & & & & & & \\
\hline \multirow[b]{2}{*}{$\square$} & & \multicolumn{3}{|l|}{ Akuisisi } & \multicolumn{3}{|l|}{ Perilaku } & \multicolumn{2}{|l|}{ Konversi } \\
\hline & & Sesi ? $\downarrow$ & \% Sesi Baru & $\begin{array}{c}\text { Pengguna Baru } \\
? ?\end{array}$ & $\begin{array}{c}\text { Rasio } \\
\text { Pentalan } \\
?\end{array}$ & $\begin{array}{c}\text { Laman/Sesi } \\
?\end{array}$ & $\begin{array}{c}\text { Durasi Sesi Rta. } \\
\qquad ?\end{array}$ & $\begin{array}{c}\text { Rasio } \\
\text { Konversi } \\
\text { Sasaran } \\
\text { ? }\end{array}$ & $\begin{array}{c}\text { Penuntasan } \\
\text { Sasaran } \\
\text { ? }\end{array}$ \\
\hline & & $\begin{array}{r}4.107 \\
\% \text { Total } \\
100,00 \% \text { (4.107) }\end{array}$ & $\begin{array}{r}74,80 \% \\
\text { Rta. untuk } \\
\text { Tampilan: } \\
74,77 \% \\
(0,03 \%)\end{array}$ & $\begin{array}{r}3.072 \\
\text { \% Total: } \\
100,03 \%(3.071)\end{array}$ & $\begin{array}{r}12,10 \% \\
\text { Rta. untuk } \\
\text { Tampilan: } \\
12,10 \% \\
(0,00 \%)\end{array}$ & $\begin{array}{r}5,18 \\
\text { Rta. untuk } \\
\text { Tampilan } 5.18 \\
(0,00 \%)\end{array}$ & $\begin{array}{r}\text { 00:02:00 } \\
\text { Rta. untuk } \\
\text { Tampilan } \\
00: 02-00 \\
(0,00 \%)\end{array}$ & $\begin{array}{r}0,00 \% \\
\text { Rita. untuk } \\
\text { Tampilan: } \\
0,00 \% \\
(0,00 \%)\end{array}$ & $\begin{array}{r}0 \\
\% \text { Total: } \\
0,00 \%(0)\end{array}$ \\
\hline$\square$ & 1. mobile & $2.793(68,01 \%)$ & $74,36 \%$ & $2.077(67,61 \%)$ & $13,28 \%$ & 4,75 & $00: 01: 34$ & $0,00 \%$ & $0 \quad(0,00 \%)$ \\
\hline$\square$ & 2. desktop & $1.244(30,29 \%)$ & $75,48 \%$ & $939(30,57 \%)$ & $9,49 \%$ & 6,14 & 00:03:01 & $0,00 \%$ & $0 \quad(0,00 \%)$ \\
\hline$\square$ & 3. tablet & $70 \quad(1,70 \%)$ & $80,00 \%$ & $56 \quad(1,82 \%)$ & $11,43 \%$ & 5,33 & $00: 01: 29$ & $0.00 \%$ & $0(0,00 \%)$ \\
\hline
\end{tabular}

Tabel 1 dapat dijelaskan bahwa beberapa perangkat yang digunakan pengunjung memiliki kategori yang berbeda dengan persentase sesi paling tinggi yaitu pengguna seluler.

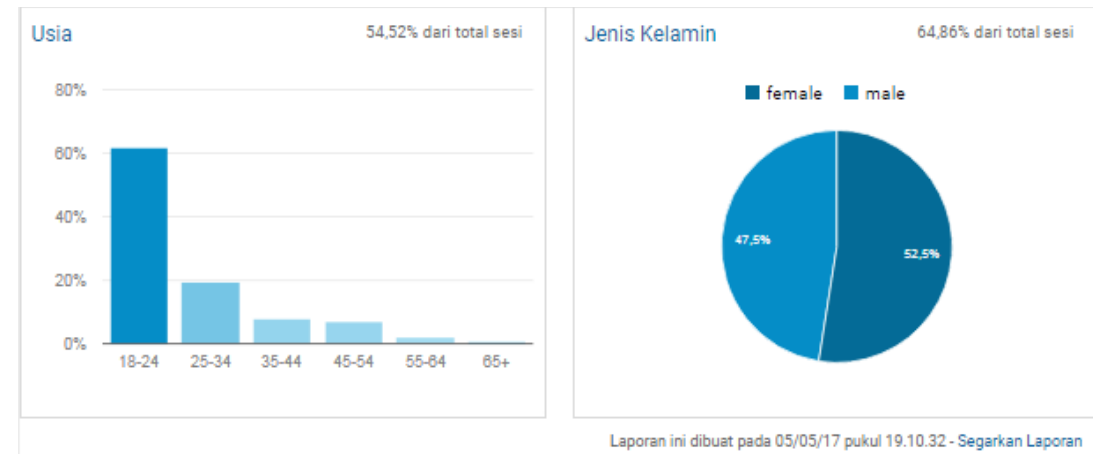

Gambar 9. Laporan Berdasarkan Usia dan Jenis Kelamin

Berdasarkan gambar 9, menunjukkan grafik bahwa usia yang paling banyak adalah diantara 18-24 tahun dan berjenis kelamin laki-laki dibandingkan dengan perempuan.

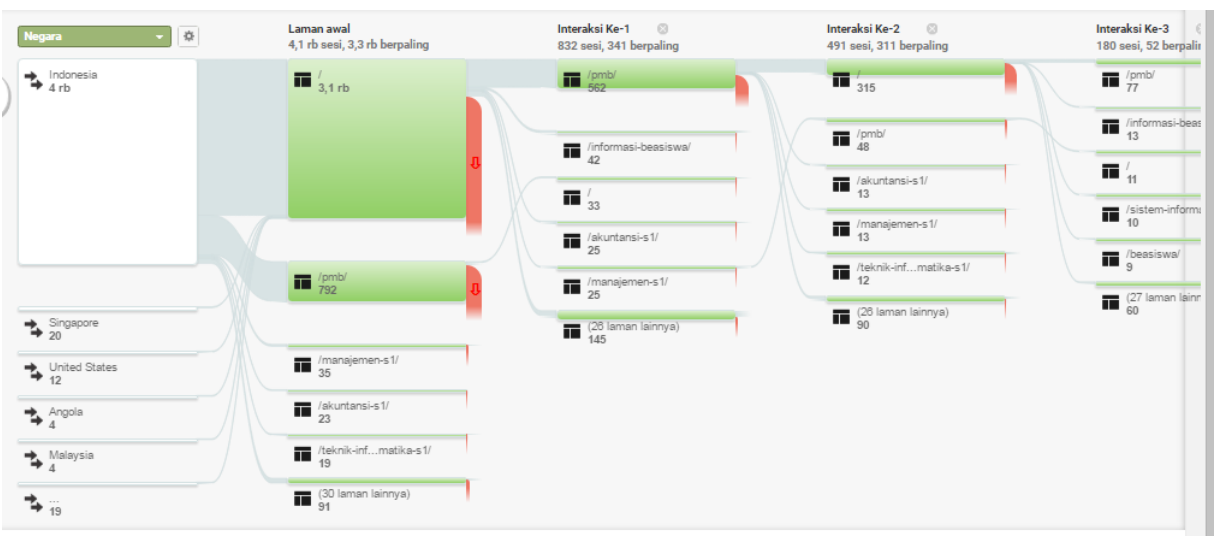

Gambar 10. Hierarki Interaksi Pengguna Website

Berdasarkan gambar 10, dapat dijelaskan bahwa pengunjung website banyak mengunjungi halaman utama kemudian ke halaman PMB, hal itu dikarenakan proses promosi periklanan ditujukan ke halaman pmb. 


\section{Information System Journal}

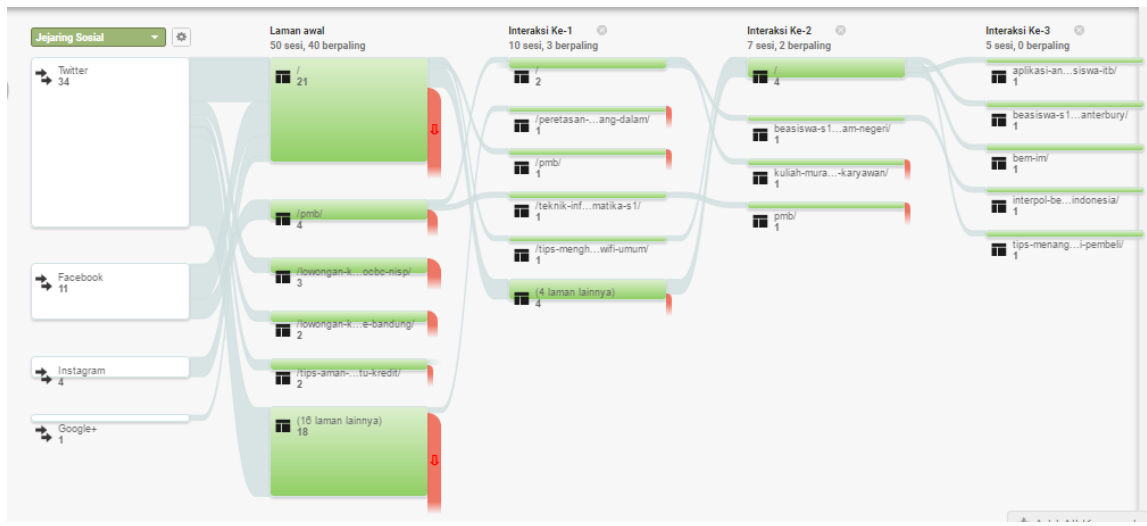

Gambar 11. Hierarki Interaksi Media Sosial

Berdasarkan peta hierarki di atas dapat dijelaskan bahwa pengunjung website melalui media sosial banyak mendapatkan trafik dari twitter, facebook dan Instagram kemudian ke halaman PMB. Dalam proses remarketing periklanan agar dapat tertarget kepada pengunjung yang sudah kita lakukan analisis dan evaluasi sebelumnya, maka langkah selanjutnya adalah melakukan tracking dengan memanfaatkan kode analitik yang didapatkan dari dashboard akun kemudian disimpan di halaman header maupun footer dari website. Berikut adalah kode tracking yang diterapkan pada halaman website.

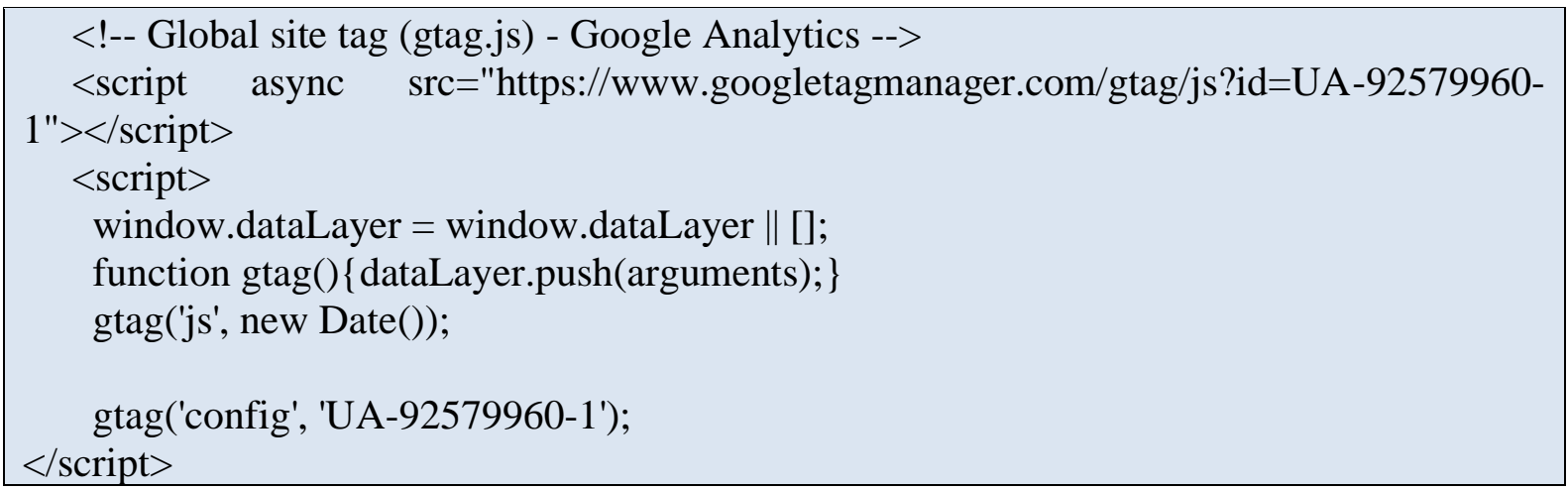

Kode property di atas wajib diterapkan agar google analytics dapat melakukan tracking terhadap semua interaksi yang terjadi pada website, kode 'UA-92579960-1' merupakan kode primary setiap akun yang dapat dikenali oleh google analytics. 


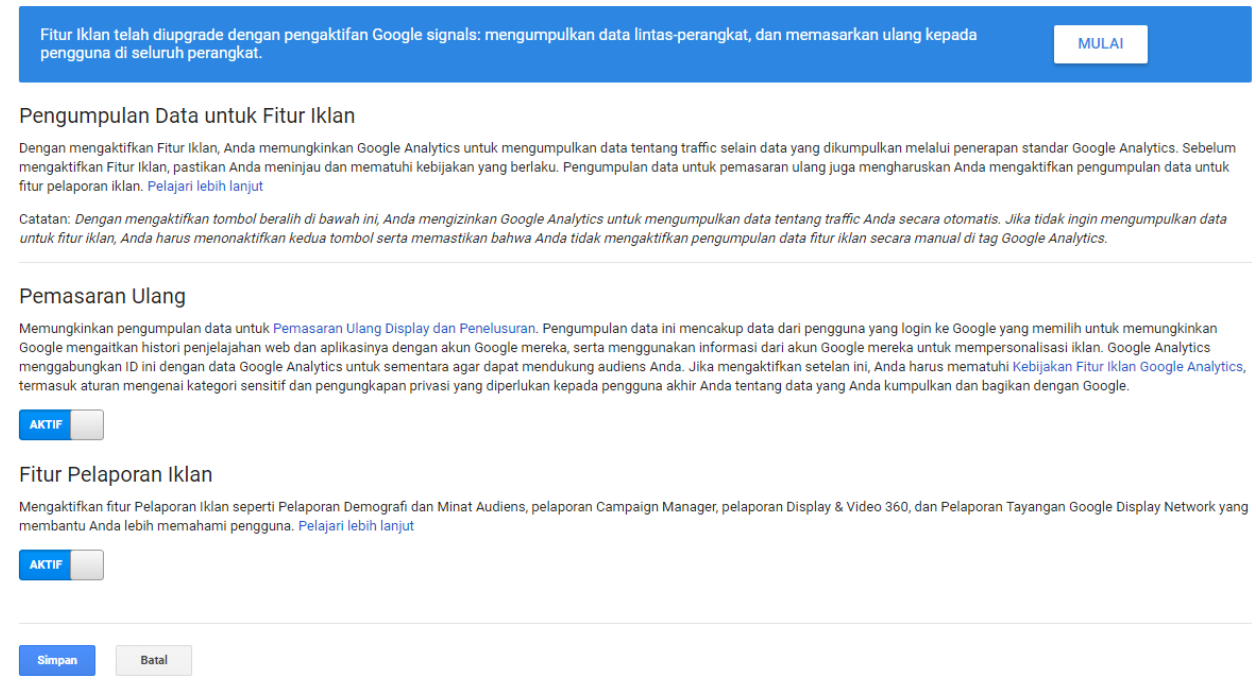

\section{Gambar 12. Panel Tracking}

Gambar 12 merupakan sebuah panel instruksi aktivasi remarketing agar kode tracking dapat terintegrasi dengan konten iklan yang kita jalankan, sehingga konten iklan akan melakukan tracking secara otomatis kepada pengguna setiap kali pengguna membuka internet maka konten iklan kita akan selalu mengikuti.

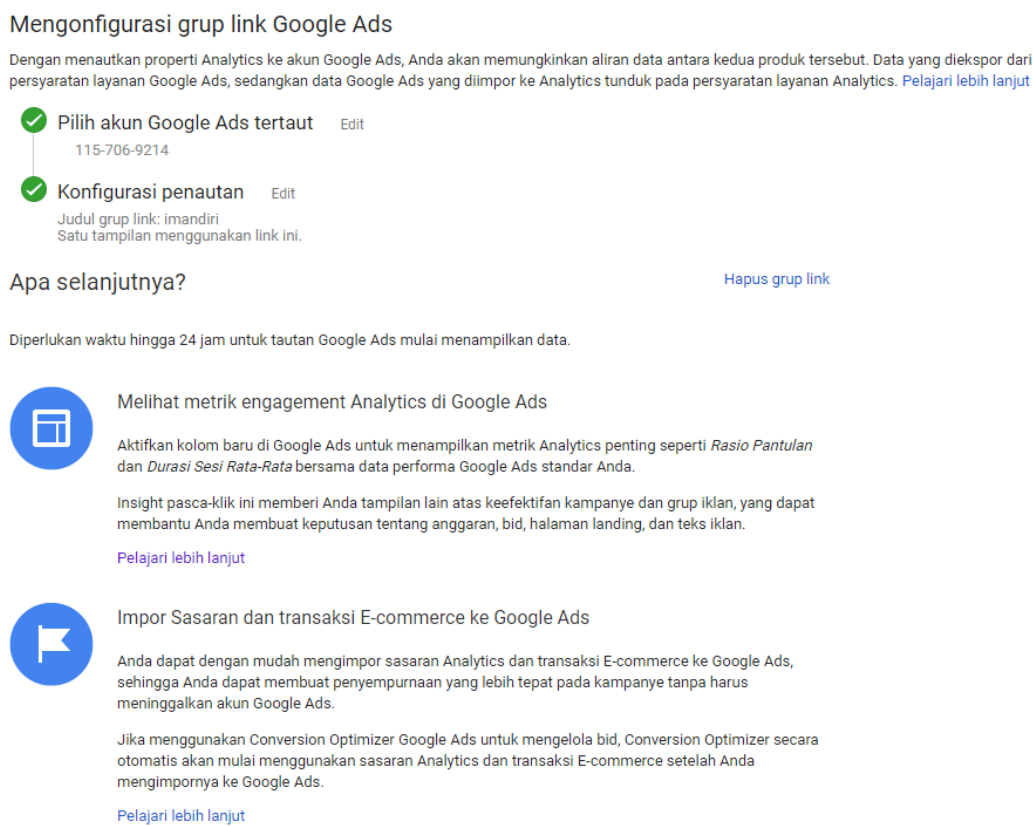

Diperlukan waktu hingga 24 jam untuk tautan Google Ads mulai menampilkan data.

Insight pasca-klik ini memberi Anda tampilan lain atas keefektifan kampanye dan grup iklan, yang dapat membantu Anda membuat keputusan tentang anggaran, bid, halaman landing, dan teks iklan. Pelajari lebih lanjut

Impor Sasaran dan transaksi E-commerce ke Google Ads

Anda dapat dengan mudah mengimpor sasaran Analytics dan transaksi E-commerce ke Google Ads, sehingga Anda danat membuat penyempurnaan yang lebih tepat pada kampanye tanpa harus meninggalkan akun Google Ads

Jika menggunakan Conversion Optimizer Google Ads untuk mengelola bid, Conversion Optimizer secara otomatis akan mulai menggunakan sasaran Analytics dan transaksi E-commerce setelah Anda mengimpornya ke Google Ads.

Pelajari lebih lanjut

\section{Gambar 13. Konfigurasi Grup Link}

Pada gambar 13, dapat dijelaskan bahwa setting konfigurasi dilakukan untuk memilih akun Google Ads mana yang akan dilakukan tracking, sehingga konten iklan yang dijalankan akan melakukan tracking dengan tepat sasaran. 


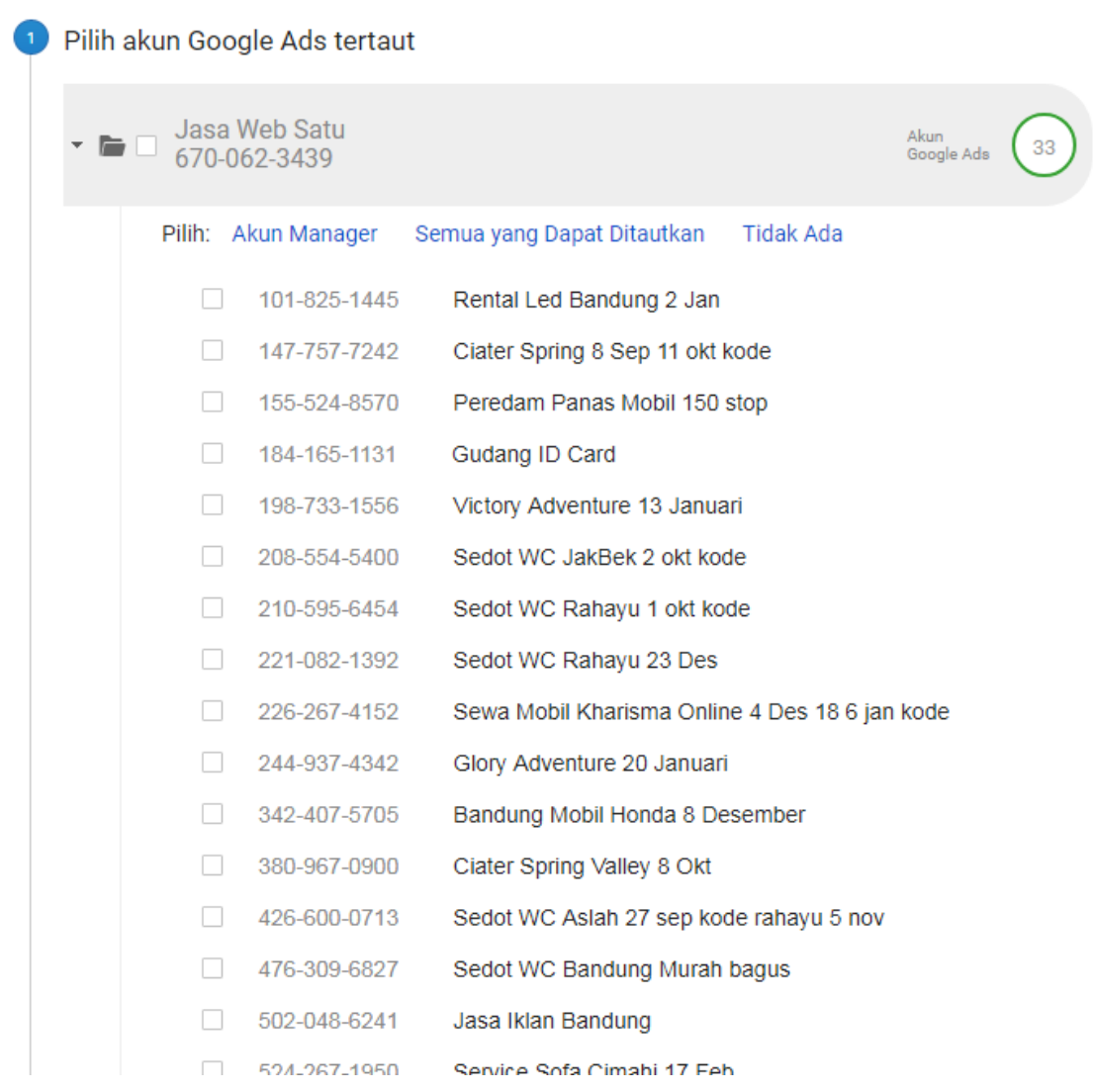

Gambar 14. Akun Terkait

Gambar 14 menjelaskan pemilihan akun Google Ads mana yang akan kita integrasikan untuk proses remarketing, sehingga pada saat iklan berjalan akan melakukan tracking melalui media perangkat pengguna maupun media sosial.

\section{PENUTUP}

Teknik remarketing merupakan salah satu teknik yang wajib diterapkan pada periklanan online, hal itu dianggap penting karena setiap iklan yang dijalankan tentunya diharapkan mendapatkan hasil sesuai dengan target pencapaian yang diharapkan, disatu sisi juga agar anggaran iklan yang kita keluarkan sebanding dengan hasil yang dicapai.

Penerapan metode remarketing tentunya tidak hanya dilakukan di Google Analytics saja, namun pada dapat pula dilakukan di dashboard Facebook Ads dengan memanfaatkan event dan konversi iklan sehingga data pengguna yang pernah melakukan interaksi dengan iklan yang ada di Facebook juga akan masuk kedalam data tracking. Dari hasil analisis yang telah dilakukan oleh penulis maka dapat diambil kesimpulan bahwa teknik pemasaran online dengan penerapan teknik remarketing ini tepat sehingga meningkatkan trafik pengunjung website institusi, dari peningkatan trafik tersebut maka peluang untuk mencapai target terbuka lebar sebab pengunjung menerima informasi terkait dengan institusi yang berdampak pada ketertarikan pengunjung terhadap institusi tersebut. Bila dibandingkan dengan pemasaran konvesional, remarketing ini juga meminimalisir biaya yang dikeluarkan, sehingga tidak alokasi biaya pemasaran dapat di alokasikan ke bidang lain untuk menunjang institusi tersebut. Hasil evaluasi yang dilakukan diharapkan dapat menjadi solusi dan rekomendasi yang baik dalam melakukan promosi online agar hasilnya dapat tertarget sesuai dengan yang diharapkan. 


\section{DAFTAR PUSTAKA}

Agustin, C. K. 2017. Pengaruh Keterlibatan Personal Terhadap Pencarian Informasi Dan Minat Pembelian (Studi Kuantitatif Pada Iklan Online Dengan Format Remarketing Ads Menggunakan Analisis Elaboration Likelihood Model). Universitas Brawijaya.

Akbar, Y. H. and M. A. Helmiawan. Penerapan Strategi Social Media Marketing Untuk Meningkatkan Penjualan Pada Dealer Mobil Toyota, Daihatsu dan Honda Bandung. Infoman's J. Ilmu-ilmu Manaj. dan Inform., vol. 12, no. 2, pp. 115-124, 2018.

Araujo, M., Y. Mejova, I. Weber, and F. Benevenuto, "Using Facebook ads audiences for global lifestyle disease surveillance: Promises and limitations," in Proceedings of the 2017 ACM on Web science conference, 2017, pp. 253-257.

Farhan, S. M. 2016. A graphical data analyzer that analysis trend of a portal traffic based on big data stored by Google Analytic.

Helmiawan, Muhammad Agreindra. 2016. Media Promosi PMB STMIK Sumedang Dengan Teknologi Augmented Reality Berbasis Android, https://www.researchgate.net/publication/323186830_Media_Promosi_PMB_STMIK_ Sumedang_Dengan_Teknologi_Augmented_Reality_Berbasis_Android, vol.10, no. 2, pp. 39-48,.

Hessain, A. A. A., 2017. Analytic Model of Ecommerce Website Using Google Analytics Tool. University of Science and Technology.

S. Othman, R. Adnan, M. G. Khairuzzaman, and N. Ismail. 2020. Analyzing User Behaviour And Page Views Based On Visitor Traffic In Kolej Universiti Poly-Tech Mara Website Using Google Analytic. MALAYSIAN J. Comput., vol. 5, no. 1, pp. 446-455.

Zarouali, B., K. Ponnet, M. Walrave, and K. Poels. 2017. Do you like cookies?' Adolescents' skeptical processing of retargeted Facebook-ads and the moderating role of privacy concern and a textual debriefing. Comput. Human Behav., vol. 69, pp. 157-165. 